\title{
Antibiotic Resistance-Renewed Fear in Gardnerella Vaginalis And Its Role In Bacterial Vaginosis
}

\author{
Suneel Bhooshan ${ }^{1}$, Sumit Gupta ${ }^{2}$ \\ Arti Agarwal $^{3}$, Pradeep Kumar ${ }^{3}$ \\ 1(Department Of Microbiology AIIMS Bhopal, India) \\ 2(Department Of Microbiology swahidmukundakakati Civil Hospital, Nalbari. Assam) \\ 3 (Department Of Microbiology S.N Medical College Agra, India)
}

\begin{abstract}
Abstrect:
Background: Bacterial vaginosis is associated with adverse gynecological and pregnancy outcomes. Diagnosis is totally depending on molecular/culture methods with clinical co-relation. In appropriate interpretation might led to complication associated with pregnancy.

Methods: In our study we have included culture and microscopy in association with clinicalhistory.Culture and microscopy was performed as per standard tests.Nugent 's scoring system was used for microscopy along with culture on blood agar and mac-conkey agar. Antibiotic susceptibility was performed by Kirby-Bauer disc diffusion method.

Results: All the isolates were found to be sensitive to imipenem and meropenem. But efficacy of ampicillin has been reduced up to a very low level (9.37\%). We also noted the increase drug resistance towards urinary antibiotics, which might be a topic of concern in treatment and outcome.

Conclusion: This study emphasizes the need of routine observation of drug resistance in bacteria so outcome of treatment will be better for clinicians and patients.
\end{abstract}

Keywords: Gardnerella vaginalis, Bacterial vaginosis, Nugent 's scoring system

\section{Introduction}

Bacterial vaginosis is the most common infection in females worldwide leading to vaginal disorders. A large population of African American women (30-50\%) is infected particularly of reproductive age 20-35 years Patterson et al., 2010 [1]. It may lead to severe conditions such as preterm delivery, preterm labor, post abortion endometritis, post-partum endometritis and low birth weight (Srinivasan and Fredricks, 2008; Swidsinskiet al., 2008; Menard et al., 2012) [2,3]. It may be a polymicrobial syndrome but recent studies have shownGardnerella vaginalis $(G$. vaginalis)also can be a primary pathogen in half of the cases of bacterial vaginosis. However, correlation of G. vaginalis becomes unclear due to lack of animal modelsTurovskiyet al., 2011 [4]. So it becomes important to look for the pathogen and study their presentation or pathogenesis. BV can be controlled by administration of antibiotics but cross-resistance between species or emerging resistance in primary pathogen becomes more important to look for.Therefore, this study was designed to access the G. vaginalis.

\section{Methods And Materials}

\subsection{Study population, Exclusion and inclusion criteria for specimens-}

A total of 160 G. vaginalis was isolated from September 2014 to January 2016 in District public health laboratorySwahidmukundakakati civil hospital,nalbariAssam.Patients presented with other complains than vaginal discharge, no clinical sign and symptoms, use of contraception, with historyof usage any antibioticsfor the last two weeks was excluded from the study.Inclusion criteria for study was clinical presentation of lower abdominal pain, itching, history of vaginal discharge, fishy odor and age group from 10-60 years.

\subsection{Aims of study-}

A total of 160 G. vaginalis was isolated from September 2014 to January 2016. Patients presented with other complaints than vaginal discharge, no clinical sign, and symptoms, usage of contraception, with the history of usage any antibiotics for last two weeks was excluded from the study. Inclusion criteria for study were clinical presentation of lower abdominal pain, itching, history of vaginal discharge, fishy odor and age group from 10-60 years.

\subsection{Identification and sensitivity of isolates -}

Two high vaginal swabs were collated from each patient. One swab was proceeded for microscopy 
gram stain following Nugent 's scoring system (According to Nugent's grading score of $>/=7$ on a Gram stained vaginal smear indicates the presence of BV (Cauciet al., 1996; Srinivasan and Fredricks, 2008; Swidsinskiet al., 2008)and another swab was cultured on Columbia blood agar and Mac-conkey agar[2,3,5,6]. $\mathrm{pH}$ of vaginal discharge was measured by indication paper (range from 1-14). In gram stain, Clue cells were observed along with other bacteria and Trichomonas vaginalis.

The patient presented with clinical symptoms(Amsel criteria) [7],Nugent's grading score 7-10, and culture positive for G. vaginalis was labeled as G.vaginosis infection. Identification of G.vaginalis was confirmed, as per standard protocols culture, microscopy, and biochemical characterization.

For the culture of G.vaginalis Columbia blood agar for $\beta$-hemolysis and Mac-conkey agar for non-lactose forming colonies were used.

Antibiotic susceptibility was performed by Kirby- Bauer disc diffusion method.Antibiogram was observed for following antibiotics,ampicillin (AMP), cefuroxime(CF), gentamycin (GM), amikacin (AK), nitrofurantoin(NZ), nalidixic acid (NA), imipenem (IMP), and meropenem (MRP).

Data analysis was done by Microsoft excel program.

\section{Result}

One hundred sixty samples were studied from female patients, presented with clinical history. TheMean age of this population was 30.88 while the range was 10-60. The isolates were cauterized against the age with their frequency in Table 1.

Table 1 G.vaginalisvaginalis distribution with respect to age.

Correlation between $\mathrm{pH}$, microscopy and culture are presented in Table 2 with respectto their frequencies.

Table 2. Correlation between Spiegel's criteria with culture positivity of Gardnerella

\begin{tabular}{|l|l|l|l|l|l|}
\hline $\mathrm{pH}$ & Gram stain & Culture & Amines test & $\begin{array}{l}\text { Number of } \\
\text { cases }\end{array}$ & Percentage \\
\hline$>5$ & GNB + other commensal flora & + & + & 102 & $63.75 \%$ \\
\hline$<5$ & $\begin{array}{l}\text { GNB }+ \\
\text { other commensal flora }\end{array}$ & + & - & 58 & $36.25 \%$ \\
\hline
\end{tabular}

\begin{tabular}{|l|l|l|}
\hline Age & Number of organism & Frequency (\%) \\
\hline 10 & 2 & $1.25 \%$ \\
\cline { 2 - 3 } & 25 & $15.62 \%$ \\
\hline $21-30$ & 58 & $36.25 \%$ \\
\hline $41-40$ & 49 & $30.62 \%$ \\
\hline $50-60$ & 13 & $8.12 \%$ \\
\hline Total Number of isolates & 160 & $8.12 \%$ \\
\hline
\end{tabular}

Fig. 1 consists the information about the recovered bacteria along with G.vaginalis. While fig. 2 shows sensitivity pattern of G.vaginalis isolates in our study. 


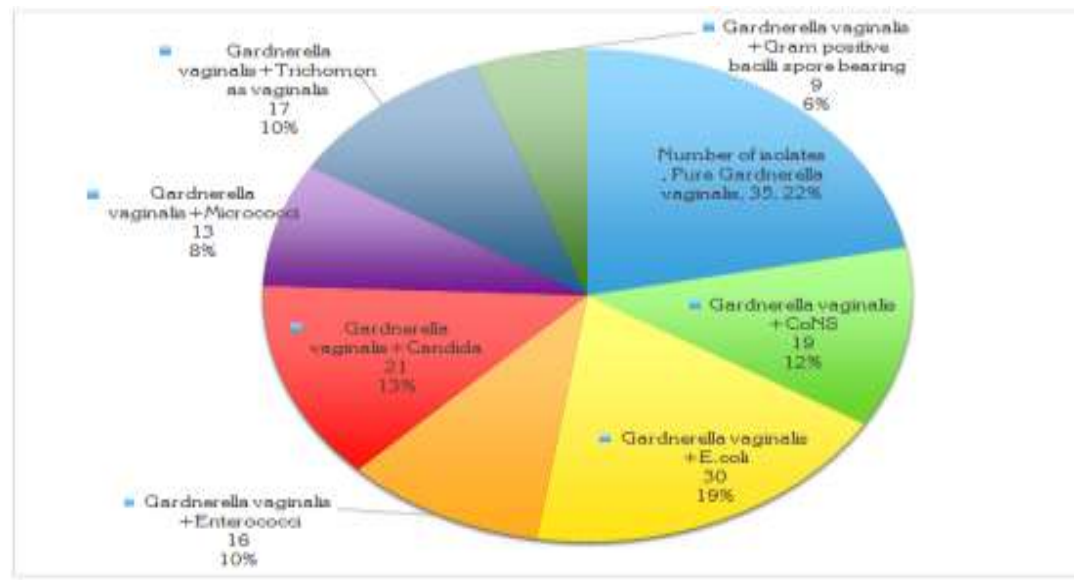

Figure 1. Various organisms isolated along with Gardnerella.

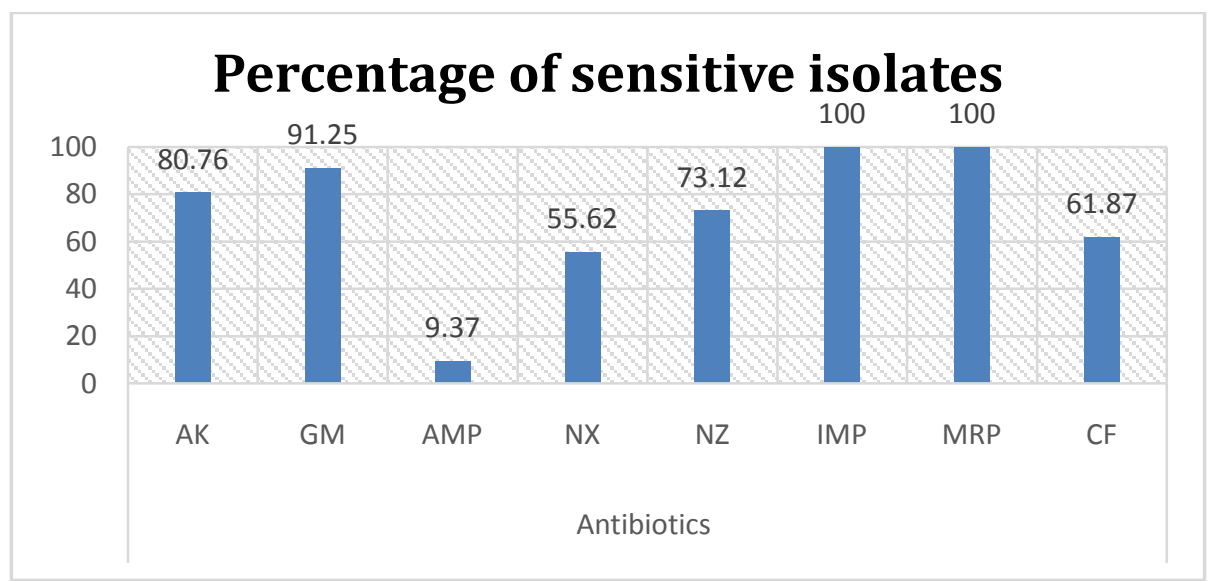

Figure 2. Drug sensitivity pattern of Gardnerellaagainst tested antibiotic.

\section{Discussion}

Bacterial vaginosis is the most common disease after urinary tract infection in female patients in which a shift occurs from a predominance of lactobacilli-dominated flora to a vaginal anaerobic environment, constituted by Gardnerella, Micrococci, Streptococci and Staphylococci. Sign and symptoms for this are itching and discharge. A wide range of organisms can causeBacterial vaginosis.

This study was primarily designed to study for antibiogram, distribution of G. vaginalis according to age and compression of culture positive rate to microscopy.

In this study most common age group infected with $G$. vaginaliswas 21-30 years standing for $36.25 \%$ cases followed by 31-40 years 30.62\% [7].The Reason behind this high positivity rates is reproductive age. Age group below 20 and above 40 had fewer isolates in compression to reported by Dhall K et all 1990 [8].

Correlation of Spiegel's criteria in our study was full filled and was in concordance with the study conducted byDhall K et all 1990 and Schaaf VM et all 1990 [8-9].Clue cells were present in 29\% of the gram stain smears which correlates study[10].

Nugent's score was 7-10 in $30.50 \%$ of the total cases which werehigher than previously reports [1113]. The reason behind this maybe person variability in scoring the smear.

The commonest organism associated with $G$. vaginalis in our study wasE. coli $30.19 \%$ similar data was presented byDutta $\mathrm{S}$ et al., in Dhaka [14], followedby spore-forming bacteria or dipthoroids22\%. The finding co-relates study conducted by SilamalaUmadevi [15].

Candida is tolerant to acidic $\mathrm{pH}$ and hence it's found in vagina.Our study showed higher prevalence rate of Candida and Coagulase negative staphylococcus 13\%, and $12 \%$ respectively which was higher in compression to Nagalakshmi Narayana-Swamy [16]. 
Mixed culture growth may be the result of contamination ofthe specimen while collecting.

Antibiotic sensitivity pattern showed all isolates of G. vaginalis was sensitive to imipenem and meropenem. Amikacin, gentamicin was also effective in $91.25 \%$ and $87.76 \%$ followed by nitrofurantoin,cefotaxime,nalidixic acid $73.12 \%, 61.87 \%$ and $55.62 \%$ respectively. High drug resistance was observed in thecase of ampicillin, only $9.37 \%$ isolates weresusceptible to ampicillin. These results of our study co-relate to study conducted byNagalakshmi Narayana-Swamy, expect in the case of fluoroquinolones (nalidixic acid) where we found more drug resistance in our isolates. We found more drug resistance to nalidixic acid in comparison to study of Nagalakshmi Narayana-Swamy [16].The reason behind it maybe the use of this drug in routine treatment for urinary tract infection cases which might have led bacteria to acquire the drug resistance. So this becomes more important to look at the treatment options for bacterial vaginosis as there is the rise in drug resistance rate in urinary antibiotics which still stand a good and safe choice for treatment. It would be wise to use antimicrobials according to requirement and with the correlation of microbiological report.

\section{Conclusion}

Bacterial vaginosis is still considered a polymicrobial infection and is a very common infection of reproductive age. Due to lack of animal models, real etiology still remains doubtful. However, some studies have demonstrated G. vaginalis as a pathogen. So it will be the best option to utilize the microbiological report along with clinical symptoms and diagnosis to reach up to any conclusion for treatment and better outcome.

\section{Limitations of study}

Further studies can be done to show the correlation between G.vaginalis and other commensal flora.

\section{Reference}

[1]. J.L. Patterson, A. Stull-Lane, P.H. Girerd, K.K Jefferson. Analysis of adherence, biofilm formation and cytotoxicity suggests a greater virulence potential of Gardnerella vaginalis relative to other bacterial-vaginosis-associated anaerobes. Microbiology2010;156: 392-399.

[2]. S.Srinivasan, DN. Fredricks. 2008. The human vaginal bacterial biota and bacterial vaginosis. Interdisciplinary Perspectives on Infectious Diseases 2008: 1-22.

[3]. A.Swidsinski, W. Mendling, V.Loening-Baucke, S.Swidsinski, Y.Dorffel, J.Scholze, H. Lochs, H.Verstraelen. An adherent Gardnerella vaginalis biofilm persists on the vaginal epithelium after standard therapy with oral metronidazole. Am. J. Obstet. Gynecol. 2008; 198:97-96.

[4]. YevgeniyTurovskiy, Katia Sutyak Noll, and Michael L. Chikindas. The etiology of bacterial vaginosis J ApplMicrobiol. 2011 May; 110(5): 1105-1128.

[5]. S. Cauci, M. Di.Santolo, G.Casabellata, K.Ryckman, S.M. Williams, S.Guaschino. Association of interleukin-1beta and interleukin1 receptor antagonist polymorphisms with bacterial vaginosis in non-pregnant Italian women. Mol. Hum. Reprod. 2007; 13:243250 .

[6]. Genital Tract Infections. In.BA Forbes, DF Sahm, AS Weissfeld, editors. Bailey and Scottís Diagnostic Microbiology. 10thed. Mosby, Inc: St. Louis; 1998. p. 363-79.

[7]. R.Amsel, P.A.Totten, C.A. Spiegel, K.C. Chen, D. Eschenbach, K.K Holmes. Nonspecific vaginitis. Diagnostic criteria and microbial and epidemiologic associations. Am J Med. 1983 Jan;74(1):14-22.

[8]. K.Dhall, C.Sokhey, A. Sarkar, G.I.Dhall, N.K.Ganguly. Isolation of Gardnerella vaginalis in cases attending the gynaecological OPD and family planning clinic of PGIMER, CHANDIGARH. Journal of obstetrics and Gynaecology 1990, $414-417$.

[9]. V.M.Schaaf, E.J. Perez-Stable, K.Borchardt. The limited value of symptoms and signs in the diagnosis of vaginal infections. Arch Intern Med. 1990; 150:1929 - 1933.

[10]. J.Abbott, Clinical and microscopic diagnosis of vaginal yeast infection: a prospective analysis. Ann Emerg Med. 1995; 25:587-591.

[11]. Q.M. Abu Shaqra. Bacterial vaginosis among a group of married Jordanian women: occurrence and laboratory diagnosis. cytobios 2001;105(408):35-43

[12]. A.G. Rouse, K.M. Gill, K. Davis. Diagnosis of bacterial vaginosis in the pregnant patient in an acute care setting.Arch.Gynaecol\&Obstet. 2009; 279(4):545-549.

[13]. N. Rizvi, S.Luby. Vaginal discharge: preparations and health seeking behaviour among

[14]. Nepalese women. J PMA 2004; 54:620.

[15]. S. Dutta, M.R. Hassan, F. Rahman, M.S.Jilani, R. Noor. Study of antimicrobial susceptibility of clinically significant microorganisms isolated from selected areas of Dhaka, Bangladesh. Bangladesh Journal of Medical Science. 2013 Jan 1;12(1):3442.

[16]. U.Silamala. S.Meeniga. A study of bacterial vaginosis with special reference to Gardnerella vaginalis. Sch. J. App. Med. Sci., 2015; 3(9D):3367-3372

[17]. N.S. Nagalakshmi, R. Padmasri, B Urvashi. Antimicrobial Sensitivity Pattern of Microorganisms Isolated from Vaginal Infections at a Tertiary Hospital in Bangalore, India.

[18]. Int MJ Med Student 2015;3 (1): 34-39 